\title{
Mechanochemistry: from Mechanical Degradation to Novel Materials Properties
}

\author{
V. Šepelák and K.-D. Becker*,† \\ Institute of Nanotechnology, Karlsruhe Institute of Technology, Hermann-von-Helmholtz-Platz 1, D-76344 \\ Eggenstein-Leopoldshafen, Germany \\ *Institute of Physical and Theoretical Chemistry, Technische Universität Braunschweig, Hans-Sommer-Strasse 10, D-38106 \\ Braunschweig, Germany
}

(Received August 30, 2011; Revised October 7, 2011; Accepted October 7, 2011)

\begin{abstract}
High-energy mechanical action applied to solid leads to destruction and diminution to the nanosize level. But on the other hand, it can induce structural changes at the nanoscale and at the atomic level which can result in novel materials properties. In this contribution, case studies will be presented concerned with the tailoring of magnetic properties of mechanically treated nanomaterials. Emphasis is placed on materials that have been synthesized by mechanochemical means and on an improved understanding of their nanomagnetism in general. The associated local structural changes of the iron containing magnetic materials discussed in the examples have been studied most suitably by ${ }^{57} \mathrm{Fe}$ Mössbauer nuclear probe spectroscopy whose results are supplemented by measurements of the magnetic properties of the mechanosynthesized nanomaterials.
\end{abstract}

Key words : Mechanochemistry, Nanomagnetism, Core-shell model, Spinels, Mössbauer spectroscopy

\section{Introduction}

M echanochemistry is concerned with the chemical behavior of solids under the action of a mechanical influence. M. Carey Lea (1823-1897) can be considered as the founding father of the field. About 120 years ago, he published the first systematic studies of mechanically induced solid state reactions involving the decomposition of copper, silver, and mercury halides. ${ }^{1,2)}$ In 1919, the term mechanochemistry was coined by Wilhelm Ostwald when he considered systematically the different modes by which energy can be introduced into a system in order to induce or promote chemical changes. ${ }^{3)}$ It took, however, many more years until the presently accepted definition of mechanochemistry was given by Heinicke in 1984 as "Mechanochemistry is that branch of chemistry which is concerned with the chemical and physical changes of solids which are induced by the action of mechanical influences". ${ }^{4)}$ The recent IUPAC Compendium of Chemical Terminology defines a mechanochemical reaction as a "chemical reaction that is induced by the direct absorption of mechanical energy". 5)

Today, mechanochemistry is well established in materials science and solid state chemistry and has developed into a broad field, see some recent reviews. ${ }^{6-9)}$ The advantages of mechanochemistry as a non-conventional synthesis technique are obvious. If, for example, the formation of zinc ferrite,

${ }^{\dagger}$ Corresponding author: K.-D. Becker

E-mail : k-d.becker@tu-braunschweig.de

Tel : +49-5313915341 Fax : +49-5313917305
$\mathrm{ZnFe}_{2} \mathrm{O}_{4}$, is required, it can be obtained by simply milling stoichiometric amounts of $\mathrm{ZnO}$ and $\mathrm{Fe}_{2} \mathrm{O}_{3}$ at room temperature for a milling time of only about two hours. ${ }^{10)}$ In comparison, the conventional thermal synthesis route would require temperatures of at least $800^{\circ} \mathrm{C}$ and several stages of sample conditioning for obtaining this reaction product. Mechanochemistry, thus, in many cases can provide a simple one-step, high-yield, lowtemperature, and low-cost route for obtaining complex oxide materials with particle sizes at the nano level. As another unusual synthetic topic, the mixing of immiscible solids shall be mentioned, leading, e.g., to the formation of solid solutions of iron and indium or of bismuth with copper and iron. ${ }^{11)}$ But also the doping of $\mathrm{TiO}_{2}$ with nitrogen has been successfully accomplished by mechanochemical means. ${ }^{12)}$ Even superhard materials, like WC can be synthesized relatively easily despite the fact that the product material is significantly harder than the milling tools. ${ }^{13)}$ Finally, as a novel field under development soft mechanochemistry ${ }^{14)}$ is to be mentioned as well as the fact that the historically most important application of mechanical activation in extractive metallurgy presently experiences a renaissance. ${ }^{15)}$

But mechanical action is not only able to bring about the formation of new compounds (this processing if often called mechanosynthesis). It is also able to deliver materials (e.g. oxides) with size reduction to the nanometer scale without changes in chemical composition. By this so-called mechanical activation structural changes at the atomic level can be induced in the bulk materials by which important materials properties can be manipulated and tailored. In general, the mechanical treatment of materials, either in mechanosynthesis or by 
mechanical activation, provides novel opportunities for the fabrication of nanostructured solids with unusual properties different from those of bulk samples.

In the context of nanomaterials, nuclear probe spectroscopies like Mössbauer spectroscopy, see below, and nuclear magnetic resonance (NMR), see e.g. Refs. 16 and 17, play an important role. Due to their local nature, they are especially suited for the investigation of mechanically treated, i.e. activated or synthesized, materials. This is even more so because diffraction techniques loose most of their resolving power when applied to nanomaterials. Therefore, these nuclear probe spectroscopies are to be regarded as most important sources for structural information on mechanically treated nanoscale materials. For the important class of iron-containing magnetic materials, ${ }^{57} \mathrm{Fe}$ Mössbauer spectroscopy is the ideally suited spectroscopic technique.

Usually, those responses to mechanical action are achieved by the use of high-energy ball mills. Powder samples introduced into the mill, for an example of a commercial laboratory mill see Fig. 1, will be thoroughly mixed and easily comminuted down to particle sizes of the order of $10 \mathrm{~nm}$. The then enormously enlarged surface area as well as the associated formation of grain boundaries and lattice defects in conjunction with the ball collisions with the materials is reason for internally occurring local structural changes as well as for the increased solid state reactivity observed in many cases which often provides the basis for unusual properties. On the other hand, the use of ball mills causes the most important obstacle to a better understanding of the mechanochemical process itself. Due to their necessarily hermetically sealed nature, no direct access is possible to the milling process at in-situ conditions. In this sense, the ball-mill represents a black box. Notable exceptions have been reported, however, where reaction processes, e.g. of self-ignition, have been studied in mills with glass vessels

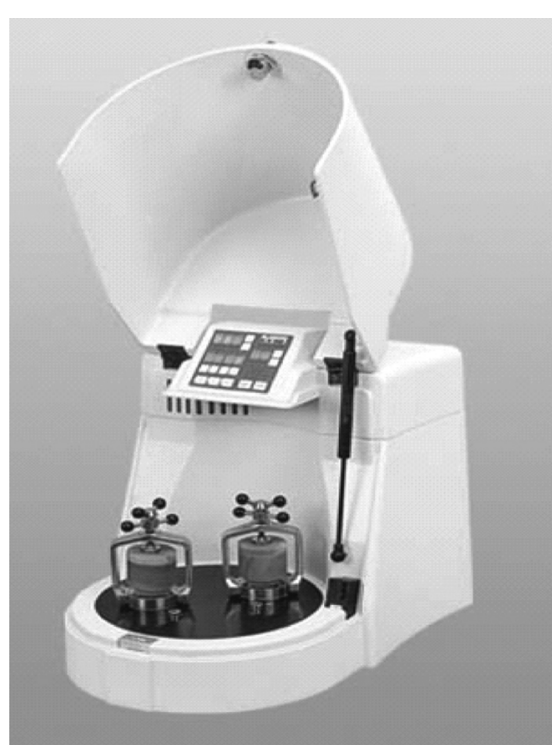

Fig. 1. Planetary high-energy laboratory mill, Pulverisette 7, Fa. Fritsch. using high-speed photography. ${ }^{18,19)}$ But also in such cases, observations are merely of macroscopic and phenomenological nature. Another feature only recently available in commercial milling systems is that the pressure and (average) temperature of reaction vessels can be monitored during the milling process by use of a small transmitter. ${ }^{20)}$

In this contribution, case studies in mechanochemistry will be reported where changes in materials properties have been obtained for materials synthesized by mechanochemical means. The examples focus on nanosized spinels and their inhomogeneous cation distributions and the changes brought about for the magnetic properties of mechanically treated spinels. Interest in such nanosized spinel ferrites has greatly increased in the past few years due to their importance in understanding the fundamentals of nanomagnetism ${ }^{21)}$ and due to their wide range of potential applications. ${ }^{22)} \mathrm{A}$ final example refers to the perovskite-like $\mathrm{BiFeO}_{3}$ which is a multiferroic compound that presently receives a lot of attention. ${ }^{23)}$

\section{Case Studies in Mechanochemistry and Nanomagnetism}

\subsection{The impact of high-energy milling on materials}

2.1.1. The formation of inhomogeneous nanoparticles

High energy-milling of materials comminutes bulk materials to very small sizes and particles of the $10 \mathrm{~nm}$ range can easily be produced. These mechanically treated materials, either mechanically activated or mechanosynthesized, have one feature in common that is not found in other synthesis routes to nanomaterials. This unique feature is only brought out by high-resolution TEM as shown in Fig. 2 for the case of nano$\mathrm{Li}_{0.5} \mathrm{Al}_{2.5} \mathrm{O}_{4}$ spinel. This and many HR-TEM micrographs of other mechanically treated materials clearly show that nanoparticles produced by milling procedures are inhomogeneous. As shown

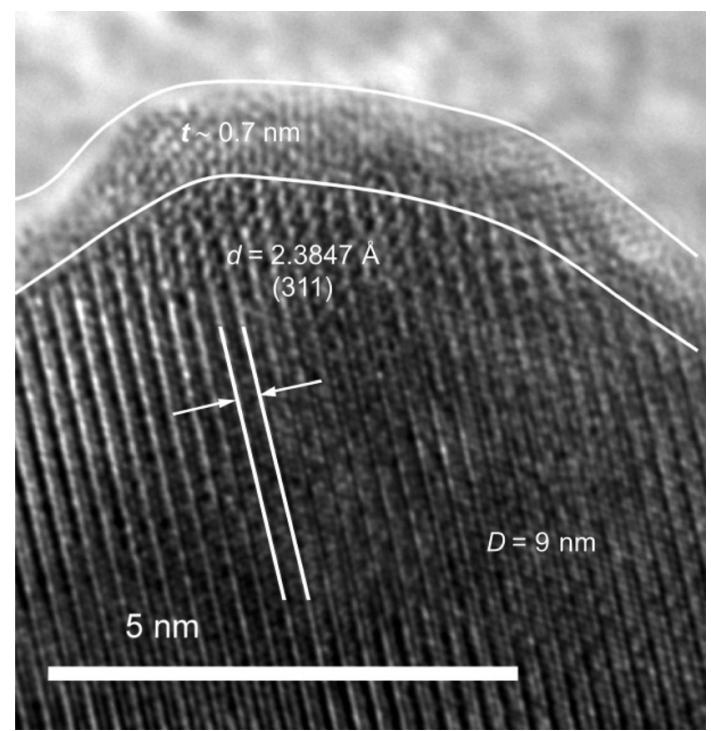

Fig. 2. High-resolution TEM micrograph of a milled, nanosized $\mathrm{Li}_{0.5} \mathrm{Al}_{25} \mathrm{O}_{4}$ spinel particle showing the existence of a core-shell structure of individual nanoparticles. 
in the figure, they exhibit a clearly defined rim region and an as well defined core region. In the following, this inhomogeneous structure will be termed the core-shell structure of nanoparticles. As it can also be recognized from Fig. 2, the shell region exhibits a disordered arrangement of atoms - in some cases surface shells can even be amorphous - while the core exhibits full crystallinity. It can also be recognized from the micrograph that the thickness of the shell region amounts to about $1 \mathrm{~nm}$. This size has been found to be characteristic for surface shell regions of mechanically treated materials, see below.

\subsubsection{Changing cation distributions in spinels}

The structure of 2-3 spinels of the type $\mathrm{MeB}_{2} \mathrm{O}_{4}$ (where 2-3 refers to the valences of $M e$ and $\mathrm{B}$ cations, respectively) provides two differently coordinated types of lattice sites for the $\mathrm{Me}^{2+}$ and $\mathrm{B}^{3+}$ cations. In the case of spinel ferrites, $M e \mathrm{Fe}_{2} \mathrm{O}_{4}, \mathrm{Me}$ stands for a wide variety of divalent cations like, e.g., $\mathrm{Ni}, \mathrm{Cu}$, $\mathrm{Mn}, \mathrm{Zn}, \mathrm{Mg}$. The ferric iron and $M e$ cations are distributed over sites (A) of tetrahedral and sites [B] of octahedral coordination by oxygen, where the number of [B]-sites is twice as large as that of (A)-sites. Thus, a detailed structural formula of $M e \mathrm{Fe}_{2} \mathrm{O}_{4}$ can be written as $\left(M e_{1-\lambda} \mathrm{Fe}_{\lambda}\right)\left[M e_{\lambda} \mathrm{Fe}_{2-\lambda}\right] \mathrm{O}_{4}$ where round and square brackets denote cations on tetrahedrally and octahedrally coordinated sites, respectively. The parameter $\lambda$ describing the distribution of cations on the two sublattices of the spinel structure is the so-called degree of inversion. It is defined as the fraction of the tetrahedrally coordinated (A)-sites occupied by $\mathrm{Fe}^{3+}$ cations. For normal spinels $\lambda=0$, for inverse spinels $\lambda=1$, and for the random cation distribution $\lambda_{\text {rd }}=2 / 3$.

As an empirical rule, it can be stated that cation distributions of spinels tend to the random distribution upon heating to elevated temperatures. ${ }^{24-27)}$ Interestingly, also the application of high pressures can lead to an increasing disorder of the cation distribution. ${ }^{28)}$ During the milling process, the impact of the balls on the material to be milled leads to pressure and temperature jumps at the points of impact. It is, thus, quite reasonable to expect a randomizing influence of milling, with $\lambda \rightarrow \lambda_{\mathrm{rd}}$, on cation distributions in spinels due to the thermal spikes and pressure jumps. The latter prediction is indeed borne out by many mechanically treated $\mathrm{MeB}_{2} \mathrm{O}_{4}$ spinels and our findings of such a randomizing tendency, with $\lambda \rightarrow \lambda_{\text {rd }}$, as a consequence of extended high-energy milling ${ }^{16,29,30)}$ are, therefore, quite reasonable as shown in Fig. 3. It should be noted that the prediction holds for near normal spinels with a low degree of inversion - where $\lambda$ increases due to milling - as well as for near inverse spinels with their starting bulk values close to $\lambda=1-$ in which case $\lambda$ decreases during the milling procedure. As is also shown in the figure, similar results are obtained for 1-3 spinels of type $M_{0.5} \mathrm{~B}_{2.5} \mathrm{O}_{4}$.

In view of the foregoing discussion, Section 2.1.1, about the formation of a core-shell structure of mechanically treated nanoparticles, the data shown in the graph for the degree of inversion represent average values for the inhomogeneous nanoparticles considered. In the framework of the core-shell model, the degree of inversion may be written as follows:

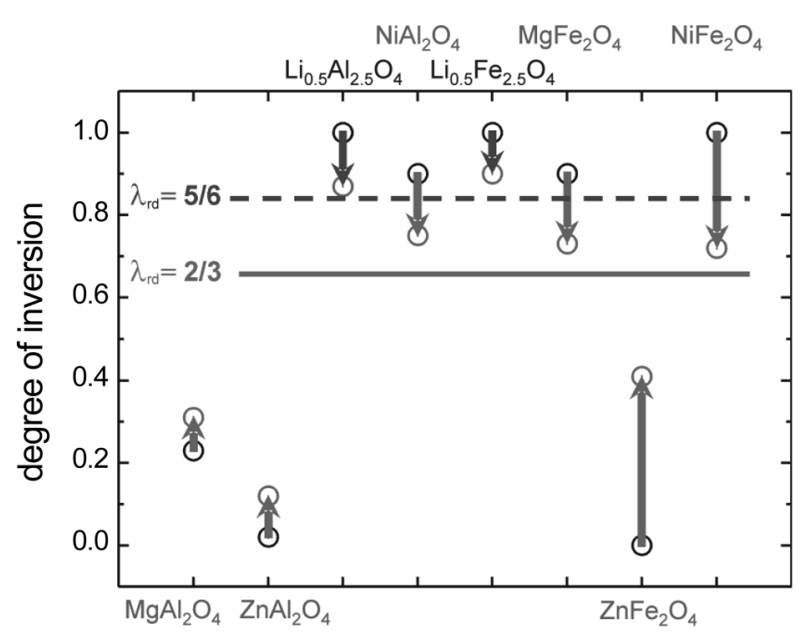

Fig. 3. Cation distributions of spinels and their changes upon high-energy milling. For spinels of type $\mathrm{MeB}_{2} \mathrm{O}_{4}$, the random distribution is given by $\lambda_{\text {rd }}=2 / 3$. For spinels of type $M_{0.5} \mathrm{~B}_{2.5} \mathrm{O}_{4} \lambda_{\text {rd }}=5 / 6$. Here, $M$, $M e$, and B denote singly, doubly, and triply charged cations.

$\lambda=x_{\mathrm{c}} \lambda_{\mathrm{c}}+x_{\mathrm{s}} \lambda_{\mathrm{s}}$ with $x_{\mathrm{c}}+x_{\mathrm{s}}=1$

where $x_{\mathrm{c}}$ and $x_{\mathrm{s}}$ represent the volume fractions of the core and the shell regions, respectively and $\lambda_{\mathrm{c}}$ and $\lambda_{\mathrm{s}}$ the corresponding degrees of inversion.

\subsection{Spinels and Nanomagnetism}

\subsection{1. $\mathrm{MgFe}_{2} \mathrm{O}_{4}$}

${ }^{57} \mathrm{Fe}$ Mössbauer spectroscopy can provide information on the local coordination, the magnetic state and the charge state of iron ions in materials. It is, thus, a very effective technique to characterize the microscopic state of iron-bearing bulk and nanoscale materials. Fig. 4 shows the Mössbauer spectrum of bulk $\mathrm{MgFe}_{2} \mathrm{O}_{4}$ at room temperature. The spectrum exhibits a sextet structure indicating the action of a large local magnetic field at the iron nuclei. The fit of the spectrum demonstrates

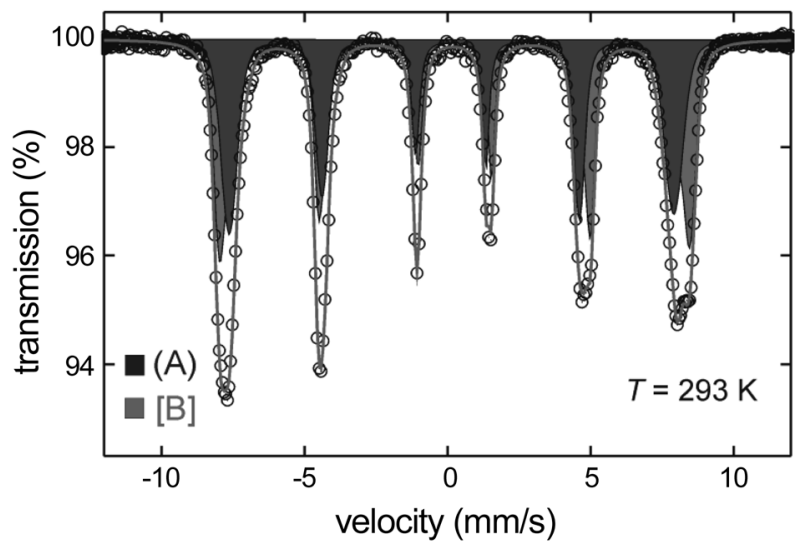

Fig. 4. Mössbauer spectrum of bulk $\mathrm{MgFe}_{2} \mathrm{O}_{4}$ at room temperature and its deconvolution into subspectra due to ferric ions on (A)- and [B]-sites. 
that the spectrum is composed of two sextets as is to be expected if the iron cations are residing in sites of tetrahedral as well as of octahedral coordination. However, the spectral resolution is poor due to the strongly overlapping lines.

For a reliable quantitative determination of the cation distribution the spectral lines need to be separated more clearly. This can be achieved by performing the measurements at low temperatures and by the application of a large external magnetic field. As shown in Fig. 5(a) for bulk $\mathrm{MgFe}_{2} \mathrm{O}_{4}$, this results in the full separation of lines with the $\mathrm{Fe}^{3+}$ ions on (A)sites giving rise to the subspectrum indicated in black and those on [B]-sites yielding the subspectrum in gray. As can be recognized, the cation distribution of bulk $\mathrm{MgFe}_{2} \mathrm{O}_{4}$ is almost inverse with $\lambda$ close to 1 . Figs. 5(b) and (c) show spectra of the same material after treating the polycrystalline material for 15 and $30 \mathrm{~min}$, respectively, in a high-energy ball mill. As seen, there is a relative increase of the integral intensity of the gray subspectrum by the mechanical treatment. This is due to a higher concentration of ferric ions on [B]-sites which now approaches almost the random distribution with $\lambda \approx 2 / 3$.

Quantitatively, the degree of inversion is calculated from the Mössbauer subspectral intensities according to $I_{(\mathrm{A})} / I_{[\mathrm{B}]}=$

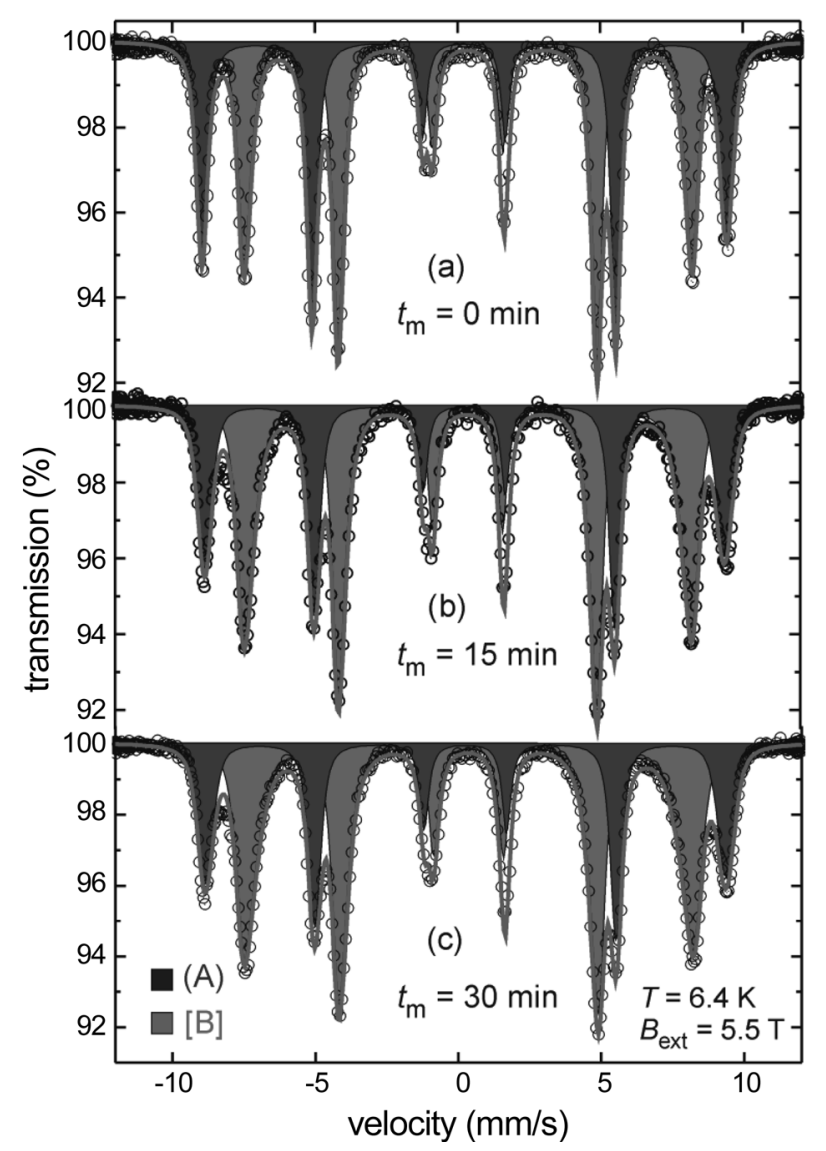

Fig. 5. Mössbauer spectra of (a) bulk $\left(t_{\mathrm{m}}=0 \mathrm{~min}\right)$ and of mechanically activated nanocrystalline $\mathrm{MgFe}_{2} \mathrm{O}_{4}$ for (b) $t_{\mathrm{m}}=15 \mathrm{~min}$ and (c) $t_{\mathrm{m}}=30 \mathrm{~min}$. The spectra were taken at $6.4 \mathrm{~K}$ in an external magnetic field of $5.5 \mathrm{~T}$ applied perpendicular to the $\gamma$-ray direction.
$\left(f_{(\mathrm{A})} / f_{[\mathrm{B}]}\right)(\lambda /(2-\lambda))$. The evaluation of the spectra shows that the starting bulk material possesses a cation distribution of $\left(\mathrm{Mg}_{0.096} \mathrm{Fe}_{0.904}\right)\left[\mathrm{Mg}_{0.904} \mathrm{Fe}_{1.096}\right] \mathrm{O}_{4}$ whereas the cation distribution after mechanical treatment for $30 \mathrm{~min}$ is given by $\left(\mathrm{Mg}_{0.244} \mathrm{Fe}_{0.756}\right)$ $\left[\mathrm{Mg}_{0.756} \mathrm{Fe}_{1.244}\right] \mathrm{O}_{4}$. For the quantitative evaluation of the site population it was assumed that the ratio of the recoil-free fractions $\left(f_{(\mathrm{A})} / f_{[\mathrm{B}]}\right)$ at $6.4 \mathrm{~K}$ equals 1 . However, a closer look at the spectra also reveals a change in the shape of the individual subspectra and that especially the lines of the [B]-subspectrum of the nanomaterial are broadened in comparison to those of the bulk sample. Obviously, local magnetic fields exhibit a noticeable spread at [B]-sites, and to a lesser extend also at (A)-sites. As will be shown below, these changes in cation distribution and spectral lineshapes represent the spectroscopic manifestations of significant changes in the magnetic properties of the spinel powder, see below.

In the following, mechanosynthesized $\mathrm{MgFe}_{2} \mathrm{O}_{4}$ will be considered in greater detail. Fig. 6 compares the spectra of bulk and nanosized mechanosynthesized $\mathrm{MgFe}_{2} \mathrm{O}_{4}$. Here, the low-temperature spectra taken in a large external magnetic field clearly reveal significant differences of the two materials. In line with Section 2.1.1, the high-quality fits of the spectra of

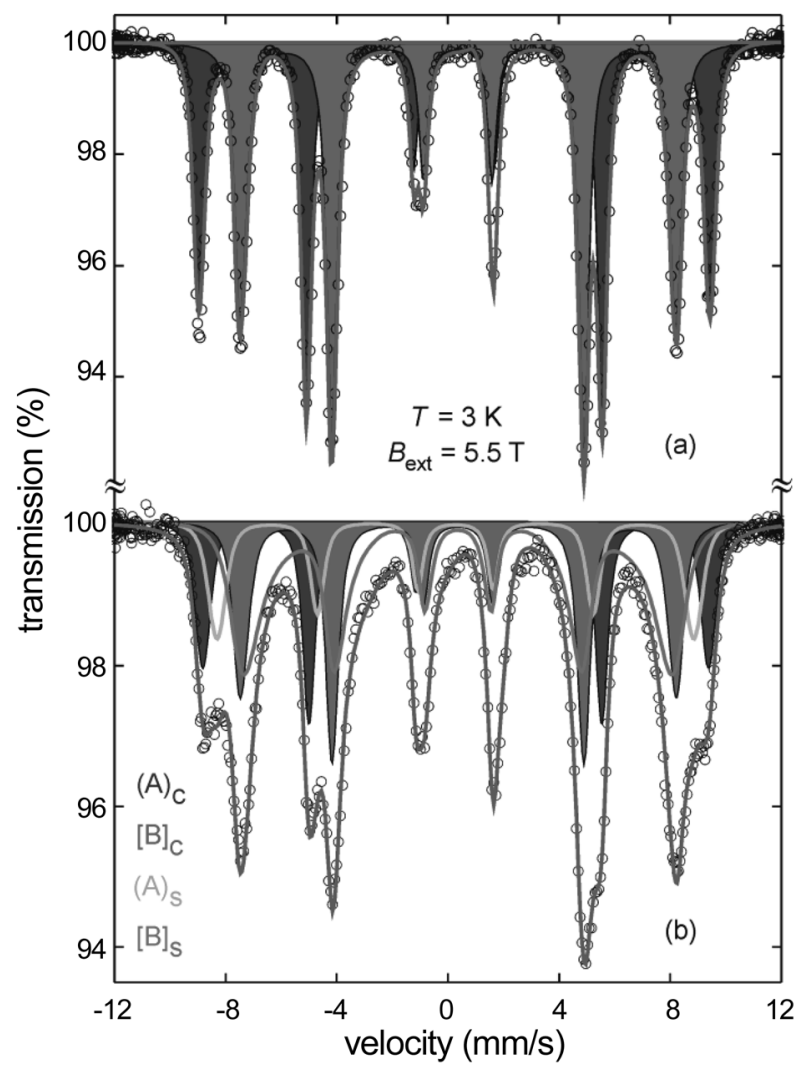

Fig. 6. Mössbauer spectra of (a) bulk $\mathrm{MgFe}_{2} \mathrm{O}_{4}$ and (b) nanosized mechanosynthesized $\mathrm{MgFe}_{2} \mathrm{O}_{4}$ taken at $3 \mathrm{~K}$ in an external magnetic field of $5.5 \mathrm{~T}$ applied perpendicular to the $\gamma$-ray direction. $(\mathrm{A})_{\mathrm{c}},[\mathrm{B}]_{\mathrm{c}}$ and $(\mathrm{A})_{\mathrm{s}},[\mathrm{B}]_{\mathrm{s}}$ denote magnetically split subspectra due to ferric ions on sites of tetrahedral and octahedral coordination in the inner core and the surface shell of $\mathrm{MgFe}_{2} \mathrm{O}_{4}$ nanoparticles, respectively. 
the nanomaterial, Fig. 6(b), have been achieved by a superposition of four sextet subspectra. Two of the subspectra account for $\mathrm{Fe}^{3+}$ ions accommodated on sites of tetrahedral and of octahedral coordination in the core region of the particles, denoted by $(A)_{c}$ and $[B]_{c}$, respectively. The two additional subspectra, denoted by $(\mathrm{A})_{\mathrm{s}}$ and $[\mathrm{B}]_{\mathrm{s}}$, are associated with the surface shell region of the nanoparticles. In order to be able to separate the core and shell contributions, it was assumed that the core of the nanoparticles retains the $\lambda$-value of the bulk material, i.e. $\lambda_{\mathrm{c}}=\lambda_{\text {bulk }}=0.90$, and that the milling effect mostly materializes in the shell region. We consider this as kind of mechanochemical cushioning effect where the mechanical stress on the core is reduced due to the formation of the disordered shell region. Applying appropriate restraints in the fits, for details see Ref. 31, a value of $\lambda_{\mathrm{s}}=0.69$ (3) is obtained for the shell region. The latter value is close to the degree of inversion of the random distribution of $\mathrm{Mg}$ and $\mathrm{Fe}$ cations on the two sublattices of the spinel structure and, thus, is compatible with the findings derived from HR-TEM. ${ }^{31)}$ In conclusion, a $\mathrm{MgFe}_{2} \mathrm{O}_{4}$ nanoparticle is found to consist of two regions, both possessing the spinel structure with, however, different cation distributions.

Another important finding relates to the alignment of the magnetic moments of the two sublattices in the external magnetic field which is characterized by the so-called canting angle denoting the angle between the external magnetic field and the sublattice magnetization. If an external field $\left(\mathrm{B}_{\text {ext }}\right)$ is applied perpendicular to the $\gamma$-ray direction, the average canting angle $\Psi$ can be determined from the intensity ratio $I_{2} / I_{1}$ of spectral lines 2 and 1 of magnetic sextets (counted from left to right) according to $\Psi=90^{\circ}-\arcsin \left\{\left[3\left(I_{2} / I_{1}\right) / 2\right] /\left[1+3\left(I_{2} / I_{1}\right) / 4\right]\right\}^{1 / 2}{ }^{32)}$ In the fit of the spectrum, it was assumed that the sublattice magnetizations of the core show perfect alignment with the external magnetic field (i.e. $I_{(\mathrm{A}) \mathrm{c} 2} / I_{(\mathrm{A}) \mathrm{c} 1}=I_{[\mathrm{B}] \mathrm{c} 2} / I_{[\mathrm{B}] \mathrm{c} 1}=4 / 3$ ) which is reflected by canting angles $\Psi_{(\mathrm{Acc}}=\Psi_{\mathrm{BBcc}}=0$. In contrast, canting angles of $\Psi_{(\mathrm{A}) \mathrm{s}}=29.1^{\circ}$ and $\Psi_{[\mathrm{B}] \mathrm{s}}=39.4^{\circ}$ were found from the intensity ratios $I_{(\mathrm{A}) \mathrm{s} 2} / I_{(\mathrm{A}) \mathrm{s} 1}$ and $I_{[\mathrm{B}] \mathrm{s} 2} / I_{[\mathrm{B}] \mathrm{s} 1}$ for the surface shell indicating that the spins on the two sublattices of this region behave differently in the external field of $5.5 \mathrm{~T}$. This is considered as a manifestation of a high degree of spin frustration due to to the nonequilibrium cation distribution and the deformed polyhedra in the surface shell of the nanoparticles.

The intensies of the subspectra indicate that about $50 \%$ of the magnetic cations are located in the shell region of the $\mathrm{MgFe}_{2} \mathrm{O}_{4}$ nanoparticles. Assuming, in a simple model, spherical shapes for the mechanosynthesized nanoparticles, the average thickness $t$ of the surface shell is estimated to about $0.85 \mathrm{~nm}$. In view of the lattice constant of $\mathrm{MgFe}_{2} \mathrm{O}_{4}$ of $0.83998 \mathrm{~nm},{ }^{33)}$ the shell thickness is very close to the lattice parameter and corresponds to about 4-5 near-surface cation layers. From comparison with several other spinels for which similar analyses have been performed $\left(t=0.91 \mathrm{~nm}\right.$ for $\mathrm{MnFe}_{2} \mathrm{O}_{4},{ }^{34)} t=1.0-1.6 \mathrm{~nm}$ for $\mathrm{CoFe}_{2} \mathrm{O}_{4}$, ${ }^{35)}$ and for the case of $\mathrm{NiFe}_{2} \mathrm{O}_{4}$ see below), it can be stated that $1 \mathrm{~nm}$ is the typical thickness of the disordered surface layer of mechanically treated nanomaterials. Another point of interest refers to the average local magnetic fields experienced by the iron nuclei in the two particle regions. It is found that the fields in the shell region $\left(\langle B\rangle_{(\mathrm{A}) \mathrm{s}}=47.71(2)\right.$ $\mathrm{T},\langle B\rangle_{[\mathrm{B}] \mathrm{s}}=50.75(3) \mathrm{T}$ ) are significantly reduced in comparison to those acting on the iron nuclei in the inner core region $\left(<B>_{(\mathrm{A}) \mathrm{c}}=50.99(6) \mathrm{T},\left\langle B>_{[\mathrm{B}] \mathrm{c}}=53.47(1) \mathrm{T}\right)\right.$ of the $\mathrm{MgFe}_{2} \mathrm{O}_{4}$ nanoparticles. This observation can be explained by frustrated superexchange interactions due to the enhanced cation disorder and by the spin canting in the surface region.

The most interesting and important observation in respect to the magnetic materials properties of the nanosized mechanosynthesized $\mathrm{MgFe}_{2} \mathrm{O}_{4}$, however, is that this material possesses an enhanced magnetization. Fig. 7 shows magnetization curves of bulk and of mechanosynthesized nanoscale material. As seen, the magnetization of the nanoscale $\mathrm{MgFe}_{2} \mathrm{O}_{4}$ does not saturate even at the highest attainable magnetic field of $5 \mathrm{~T}$. This is in contrast with the magnetic behavior of the bulk material whose magnetization reaches its saturation value of $M=33.4 \mathrm{emu} / \mathrm{g}$ already at low fields. By extrapolating the high-field region of the $M\left(B_{\text {ext }}\right)$ curve to infinite field, the saturation magnetization for the nanomaterial is estimated to about $50 \mathrm{emu} / \mathrm{g}$, which represents an enhancement of about $50 \%$. Another magnetic parameter of interest is the so-called magnetic hardness. It is found that the mechanosynthesized nanoscale $\mathrm{MgFe}_{2} \mathrm{O}_{4}$ exhibits an enhanced magnetic hardness and that the coercive field of the nanomaterial $\left(H_{\mathrm{C}} \approx 0.1 \mathrm{~T}\right)$ is about 20 times larger than that of the bulk $\mathrm{MgFe}_{2} \mathrm{O}_{4}$ $\left(H_{\mathrm{C}} \approx 5 \mathrm{mT}\right)$.

The above information on the cation distribution is essential in respect to the interpretation of the changed magnetic properties, i.e. of the enhanced magnetization of the nanosized mechanosynthesized $\mathrm{MgFe}_{2} \mathrm{O}_{4}$. In the bulk material with $\lambda \approx 0.9, \mathrm{Mg}^{2+}$ and $\mathrm{Fe}^{3+}$ ions are distributed over the two sublattices as indicated above. If the antiferromagnetic nature of the magnetic moments of the sublattices (indicated by arrows) is accounted for, the bulk sample can be described as $\left(\mathrm{Mg}_{0.096} \mathrm{Fe}_{0.904} \uparrow\right)\left[\mathrm{Mg}_{0.904} \mathrm{Fe}_{1.096} \downarrow\right] \mathrm{O}_{4}$. Because $\mathrm{Mg}^{2+}$ ions possess

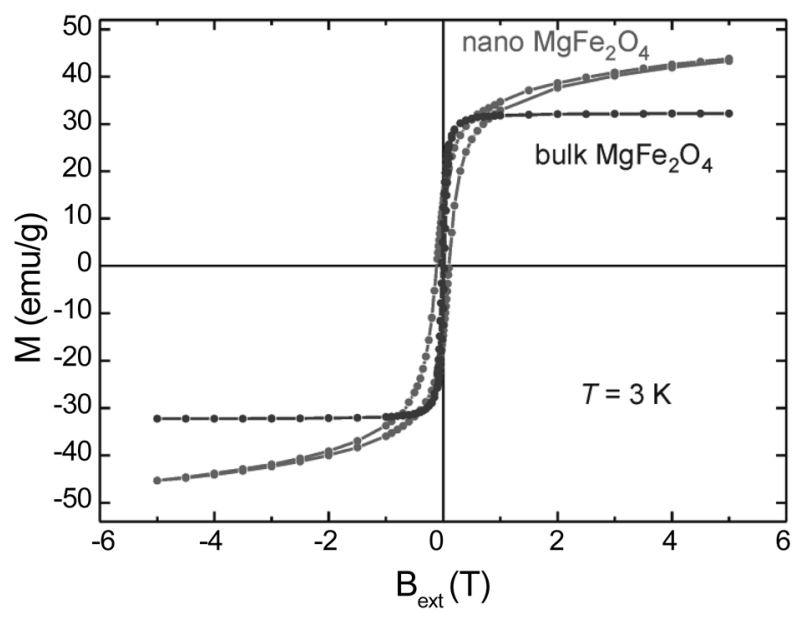

Fig. 7: The magnetization hysteresis loops for a bulk and a nanosized mechanosynthesized $\mathrm{MgFe}_{2} \mathrm{O}_{4}$ sample. The loops were measured at $3 \mathrm{~K}$ after field-cooling with $B_{\text {ext }}=5 \mathrm{~T}$. 
no magnetic moment, the total magnetic moment $\mu$ of $\mathrm{MgFe}_{2} \mathrm{O}_{4}$ is due to the uncompensated magnetic moments of the ferric cations. Therefore, the magnetic moment per formula unit can be calculated from the degree of inversion and the canting angles $\Psi$ according to

$$
\mu=\mu_{[\mathrm{B}]}-\mu_{(\mathrm{A})}=(2-\lambda) \cdot \mu_{\mathrm{Fe}} \cdot \cos \Psi_{[\mathrm{B}]}-\lambda \cdot \mu_{\mathrm{Fe}} \cdot \cos \Psi_{(\mathrm{A})}
$$

where $\mu_{\mathrm{Fe}}$ represents the magnetic moment of the $\mathrm{Fe}^{3+}$ cations. According to quantum mechanics, the magnetic moment of an ion is given by $\mu_{\text {ion }}=2[\mathrm{~S}(\mathrm{~S}+1)]^{1 / 2} \mu_{\mathrm{B}}$ where $\mathrm{S}$ represents the spin of the ion and $\mu_{\mathrm{B}}$ is the Bohr magneton $\left(\mu_{\mathrm{B}}=9.27410^{-21} \mathrm{emu}\right)$. For the high-spin $\mathrm{Fe}^{3+}$ cations $\mathrm{S}=5 / 2$ holds and, thus, $\mu_{\mathrm{Fe}}=$ $5.92 \mu_{\mathrm{B}}$. For the bulk material and for the core region, this yield the following magnetic moment per formula unit $\mu_{\mathrm{c}}=\mu_{\mathrm{bulk}}=$ $2(1-\lambda) \cdot \mu_{\mathrm{Fe}} \approx 0.2 \mu_{\mathrm{Fe}}=1.18 \mu_{\mathrm{B}}$ where it has been assumed that the sublattice magnetizations are fully aligned with the external magnetic field. From $M=\mathrm{N}_{\mathrm{A}} \mu_{\text {bulk }} / \mathrm{m}$, a saturation magnetization of $M=33.0 \mathrm{emu} / \mathrm{g}$ is calculated according to Eq. (2) on the basis on the above data derived from Mössbauer spectroscopy. Here, $\mathrm{N}_{\mathrm{A}}$ is the Avogadro constant and $\mathrm{m}$ the molar weight of $\mathrm{MgFe}_{2} \mathrm{O}_{4}\left(m_{\mathrm{MgFe} 204}=199.99 \mathrm{~g} / \mathrm{mol}\right)$. The calculated value is in excellent agreement with the experimental value of $33.4 \mathrm{emu} / \mathrm{g}$ for bulk $\mathrm{MgFe}_{2} \mathrm{O}_{4}$. On the other hand, the values of $\lambda_{\mathrm{s}}=0.69, \Psi_{(\mathrm{A}) \mathrm{s}}=29^{\circ}$, and $\Psi_{[\mathrm{B}] \mathrm{s}}=39^{\circ}$ obtained from Mössbauer spectroscopy lead to an effective magnetic moment of $\mu_{\mathrm{s}} \approx 0.41 \mu_{\mathrm{Fe}}=2.43 \mu_{\mathrm{B}}$ for the shell region, Eq. (2). Thus, with almost equal numbers of ferric ions in the cores and shells, the magnetization of the shell is predicted to be about two times larger than that of the core. In general, it is the competition between the effects of spin canting (which normally tends to reduce the magnetic moment) and of ionic disorder (which in the present case brings about an increase of the magnetic moment of the shell) which is responsible for the experimental changes in magnetization upon mechanical treatment.

If a spherical shape of the particle is assumed, the relative enhancement of magnetization $\varepsilon=\left(M_{\text {nano }}-M_{\text {bulk }}\right) / M_{\text {bulk }}$ due to mechanical treatment can be estimated in the framework of the core-shell model. Denoting the particle diameter by $D$ and the thickness of the surface shell by $t$, the relative enhancement is given by

$$
\varepsilon=\frac{\int_{0}^{(D / 2)-t} \mu_{c} 4 \pi r^{2} d r+\int_{(D / 2)-t}^{D / 2} \mu_{s} 4 \pi r^{2} d r-\frac{4}{3} \pi\left(\frac{D}{2}\right)^{3} \mu_{b u l k}}{\frac{4}{3} \pi\left(\frac{D}{2}\right)^{3} \mu_{b u l k}}
$$

With $D=8.5 \mathrm{~nm}$ and $t=0.85 \mathrm{~nm}$, and the above assumption of $\mu_{\text {bulk }}=\mu_{\mathrm{c}}$, the theoretically estimated value of $54 \%$ obtained from Eq. (3) is in excellent agreement with the enhancement of about $50 \%$ observed experimentally in the present case. As seen, the most significant cause for the enhancement is due to the different cation distributions in the core and shell region according to which the surface shell possesses a magnetization two times larger than that of the core region.
At elevated temperatures, the nanosized $\mathrm{MgFe}_{2} \mathrm{O}_{4}$ is found to be metastable with respect to structural changes. ${ }^{31)}$ During annealing at a given temperature, the individual nanoparticles of the mechanosynthesized material grow in size. In parallel, the experimental magnetization of the material changes in dependence of $D$. This is shown in Fig. 8 for magnetic measurements performed at $3 \mathrm{~K}$. The thermally induced decrease of the saturation magnetization suggests that the shell-to-core volume ratio of the material decreases with increasing annealing temperatures. Obviously, this large variation in magnetization offers ample opportunity for manipulating and tailoring the magnetic properties of these nanomaterials.

In the following, another estimate of the shell thickness will be attempted that is based on this information on size-dependent magnetic properties and on the assumptions that the nanoparticles possess a spherical shape and that the thickness $t$ of the surface shell is independent of their diameter $D$. Then, in the framework of the core-shell model, the saturation magnetization of the core-shell particles is given by

$$
\begin{aligned}
& M_{\text {sat }}=\frac{\frac{N_{A}}{m}\left(\int_{0}^{(D / 2)-t} \mu_{c} 4 \pi r^{2} d r+\int_{(D / 2)-t}^{D / 2} \mu_{s} 4 \pi r^{2} d r\right)}{\frac{4}{3} \pi\left(\frac{D}{2}\right)^{3}} \\
& =M_{c}\left(1-\frac{2 t}{D}\right)^{3}+M_{s}\left[1-\left(1-\frac{2 t}{D}\right)^{3}\right]
\end{aligned}
$$

or

$$
\left(M_{s}-M_{s a t}\right)^{1 / 3}=\left(M_{s}-M_{c}\right)^{1 / 3}\left(1-\frac{2 t}{D}\right)
$$

Here, $M_{\mathrm{s}}$ and $M_{\mathrm{c}}$ represent the saturation magnetizations in cases where the whole particle of diameter $D$ is either of the core or of the shell type, respectively.

Fig. 9 shows the graph resulting under the assumption that, as shown above, $M_{\mathrm{s}}=2 M_{\mathrm{c}}=2 M_{\text {bulk }}=66.8 \mathrm{emu} / \mathrm{g}$. As can

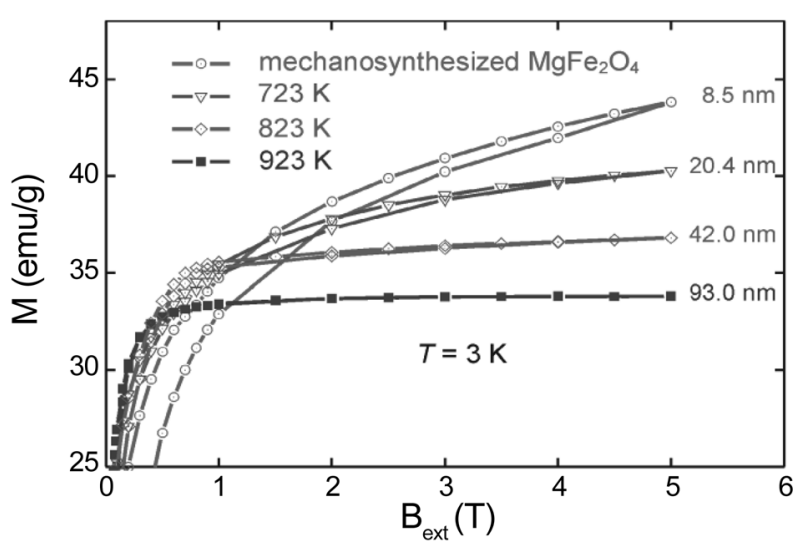

Fig. 8. Particle size-dependent magnetization loops of nanoscale mechanosynthesized and subsequently annealed $\mathrm{MgFe}_{2} \mathrm{O}_{4}$ samples measured at $3 \mathrm{~K}$. The annealing temperatures and corresponding particle sizes are shown in the figure. 


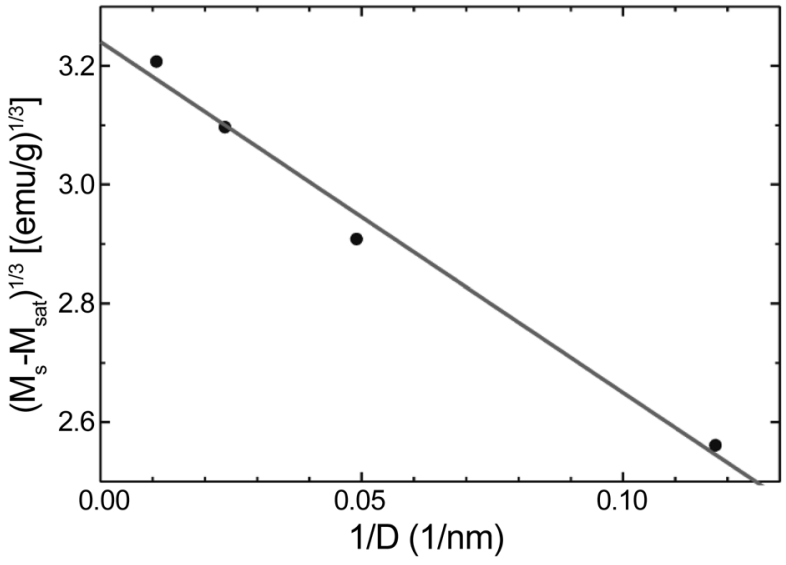

Fig. 9. $\left(M_{\mathrm{s}}-M_{\mathrm{sat}}\right)^{1 / 3}$ as a function of $1 / D$ for mechanosynthesized $\mathrm{MgFe}_{2} \mathrm{O}_{4}$ according to Eq. (5), data from Fig. 8.

be seen, the present data, Fig. 8, result in a good linear relationship. From the linear fit to the data points, one obtains the values of $M_{\mathrm{s}}-M_{\mathrm{c}} \approx 34 \mathrm{emu} / \mathrm{g}$ and $t \approx 0.91 \mathrm{~nm}$. Both results are close to the expected values and this agreement, thus, provides further independent support to the core-shell model presented in the present paper.

\subsection{2. $\mathrm{NiFe}_{2} \mathrm{O}_{4}$}

Also nickel ferrite, $\mathrm{NiFe}_{2} \mathrm{O}_{4}$, adopts the spinel structure. ${ }^{36)}$ From high-resolution TEM, mechanosynthesized $\mathrm{NiFe}_{2} \mathrm{O}_{4}$ particles are found to exhibit the typical core-shell structure with a thickness of the disordered shell of approximate $1 \mathrm{~nm}$ and particle diameters ranging between 6 to $13 \mathrm{~nm} .{ }^{37}$ Again, as in the case of $\mathrm{MgFe}_{2} \mathrm{O}_{4},{ }^{57} \mathrm{Fe}$ Mössbauer spectra of the bulk and of the nanomaterial at room temperature show strongly overlapping lines not suitable for quantitative determination of site populations. As shown in Fig. 10, Mössbauer spectra of enhanced resolution can be obtained by measurements at low temperatures and in a high external magnetic field. In the case of the bulk material (Fig. 10(a)), the spectrum is composed of two clearly resolved sextets due to $\mathrm{Fe}^{3+}$ ions on (A)- and [B]-sites. The mechanosynthesized $\mathrm{NiFe}_{2} \mathrm{O}_{4}$ on the other hand shows a complex spectrum due to the contributions from core and shell regions (Fig. 10(b)). The analysis using four sextets reveals that, while the core of a $\mathrm{NiFe}_{2} \mathrm{O}_{4}$ nanoparticle exhibits an inverse spinel structure $\left(\lambda_{c}=1\right)$, the surface shell is structurally disordered with a nearly random distribution of cations $\left(\lambda_{\mathrm{s}} \approx 0.67\right)$. The structural disorder of the shell region is also reflected by the canted spin arrangement yielding canting angles of $\Psi_{(\mathrm{A}) \mathrm{s}} \approx 28^{\circ}$ and $\Psi_{[\mathrm{B}] \mathrm{s}} \approx 40^{\circ}$ which contrasts the data for the ordered core with $\Psi_{(\mathrm{A}) \mathrm{c}} \approx 0^{\circ}$ and $\Psi_{[\mathrm{B}] \mathrm{c}} \approx 0^{\circ}$. It is also concluded from the analysis of the Mössbauer spectra that about $50 \%$ of iron cations are located in the shell part of the core-shell structure of the nanosized mechanosythesized $\mathrm{NiFe}_{2} \mathrm{O}_{4}$. From this observation, the thickness of the shell can be derived as $t \approx 1 \mathrm{~nm}$ which is in good agreement with the above cited results from TEM. ${ }^{37)}$

Fig. 11 shows the magnetization of the nanosized mecha-

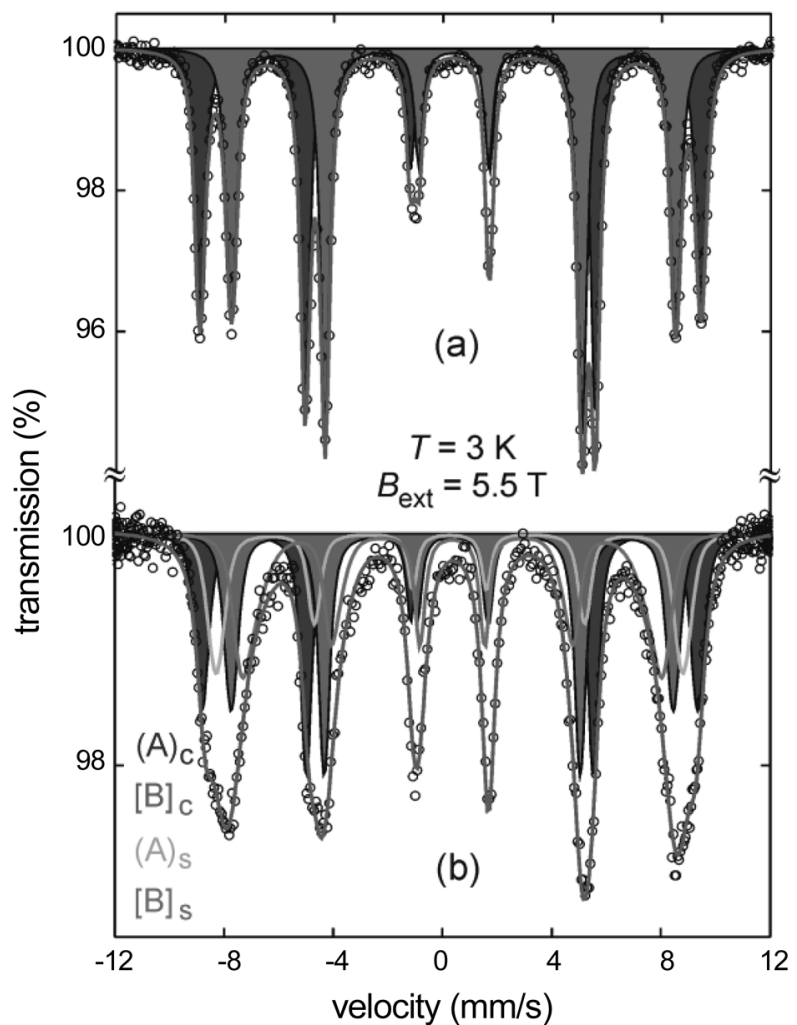

Fig. 10. Mössbauer spectrum of (a) bulk $\mathrm{NiFe}_{2} \mathrm{O}_{4}$ and of (b) nanosized mechanosynthesized $\mathrm{NiFe}_{2} \mathrm{O}_{4}$. Spectra have been taken at $3 \mathrm{~K}$ in an external magnetic field of $5.5 \mathrm{~T}$ applied perpendicular to the $\gamma$-ray direction.

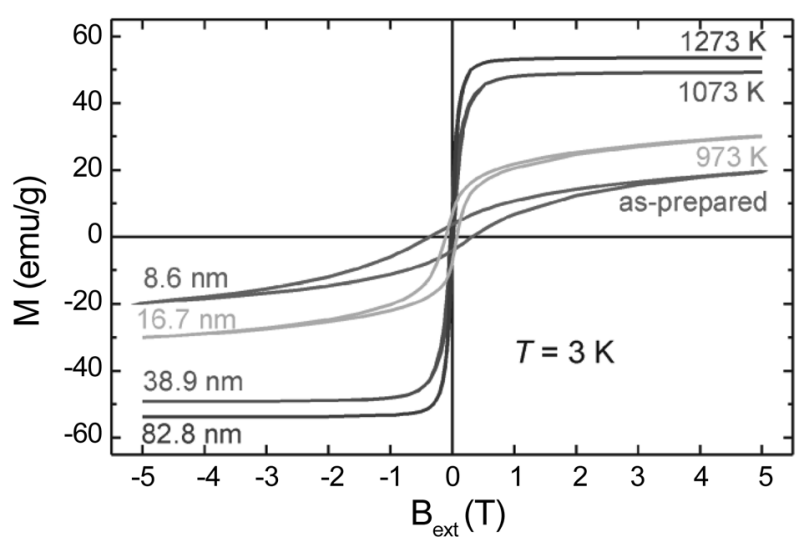

Fig. 11. The field-cooled magnetization hysteresis loops measured at $3 \mathrm{~K}$ for mechanosynthesized and subsequently annealed $\mathrm{NiFe}_{2} \mathrm{O}_{4}$ samples. The annealing temperatures and corresponding particle sizes are shown in the figure.

nosynthesized (as prepared and annealed) material. Because of the structural metastability of mechanically treated nanomaterials, particles grow during annealing at elevated temperatures. As a consequence, magnetization is significantly enhanced with rising annealing temperatures and annealing at $1273 \mathrm{~K}$ yields a magnetization curve that is almost identical to that of bulk $\mathrm{NiFe}_{2} \mathrm{O}_{4}$. As seen, the saturation magnetization 
of the as prepared nanosized material $(24.3 \mathrm{emu} / \mathrm{g})$ is considerably smaller than that of the $1273 \mathrm{~K}$-material (53.6 emu/g). The increase of the annealing temperatures, i.e. of particle sizes, is also accompanied by a continuous decrease of the coercive field from $H_{\mathrm{C}}=0.35 \mathrm{~T}$ (before annealing) to $H_{\mathrm{C}}=$ $0.013 \mathrm{~T}$ for the sample after annealing at $1273 \mathrm{~K}$ indicating a strong magnetic softening of the material. Thus, both magnetization and magnetic hardness of nanosized mechanosynthesized $\mathrm{NiFe}_{2} \mathrm{O}_{4}$ can be tailored in a wide range by choosing appropriate annealing temperatures.

As seen from Fig. 10(a), bulk $\mathrm{NiFe}_{2} \mathrm{O}_{4}$ is an almost inverse spinel $(\lambda \approx 1)$ with a cation distribution close to $(\mathrm{Fe} \uparrow)[\mathrm{NiFe} \downarrow] \mathrm{O}_{4}$. With the antiferromagnetic coupling of the $\mathrm{Fe}^{3+}$ cations on (A)- and [B]-sublattices, their magnetic contribution vanishes and, thus, the total magnetization of bulk $\mathrm{NiFe}_{2} \mathrm{O}_{4}$ is almost exclusively due to the contribution made by the $\mathrm{Ni}^{2+}$ ions $\left(\mu \approx \mu_{\mathrm{Ni}} \approx 2.83 \mu_{\mathrm{B}}\right)$. This simple model yields a predicted saturation magnetization of $67.4 \mathrm{emu} / \mathrm{g}$, Eq. (2), which is in reasonable agreement with the experimental value, see below.

In the framework of the core-shell model, the near inverse cation distribution of bulk nickel ferrite spinel prevails also in the core regions of the mechanosynthesized nanomaterial. However, due to the contribution of a second type of magnetic cations, a straight-forward interpretation of the saturation magnetization of the nanosized mechanosynthesized $\mathrm{NiFe}_{2} \mathrm{O}_{4}$ is not possible. Qualitatively, the reduction of about $50 \%$ in saturation magnetization due to the formation of a shell region containing about $50 \%$ of iron cations suggests the conclusion that the magnetization contribution of the shell must be close to zero. Under such an assumption of a magnetically "dead" shell region, Eq. (5) can be applied with $M_{\mathrm{s}}=0$, yielding the plot shown in Fig. 12. As seen, a good linear relationship is observed from which a shell thickness of $t=1.1 \mathrm{~nm}$ can be derived and a saturation magnetization of the core/bulk of $M_{\mathrm{c}}=57.2 \mathrm{emu} / \mathrm{g}$. The latter value is close to the saturation magnetization of $54.5 \mathrm{emu} / \mathrm{g}$ measured for bulk $\mathrm{NiFe}_{2} \mathrm{O}_{4}{ }^{36)}$ Also, the shell thickness obtained is in reasonable agreement with the above values estimated from TEM and from

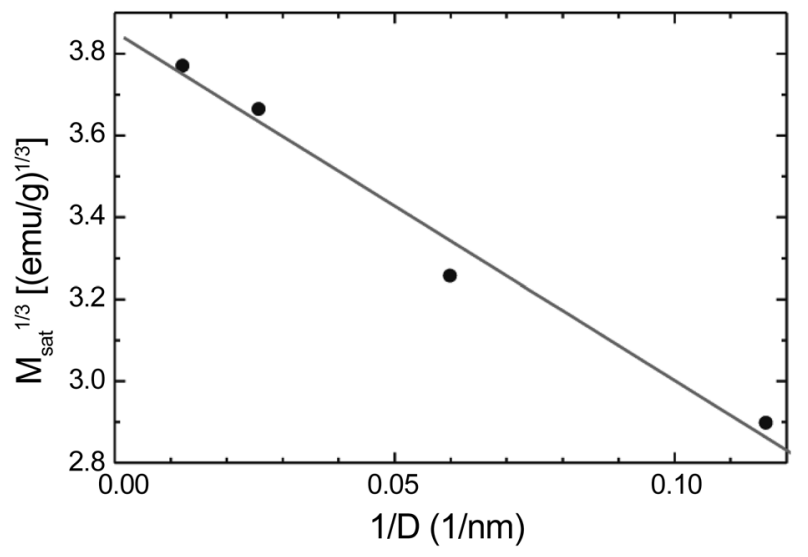

Fig. 12. Saturation magnetization of the nanosized mechanosynthesized $\mathrm{NiFe}_{2} \mathrm{O}_{4}$ as a function of $1 / D$, data from Fig. 11, see text. the Mössbauer experiments. This confirms again the general conclusion that $1 \mathrm{~nm}$ is the typical thickness for the shell in the inhomogeneous core-shell structure of mechanosynthesized materials. ${ }^{37)}$ Finally we note that $1 \mathrm{~nm}$ is also the typical thickness of the grain boundary region in nonmagnetic nanocrystalline materials prepared by mechanochemical routes. ${ }^{16,17)}$

\subsection{Nanomagnetism of mechanosynthesized $\mathrm{BiFeO}_{3}$}

Also in the case of the rhombohedrally distorted perovskite $\mathrm{BiFeO}_{3}$, the mechanochemically synthesized material possesses magnetic properties significantly different from those of the bulk material prepared by the conventional thermal ceramic route. This is shown in Fig. 13, where magnetization curves of the two materials are displayed. As seen, at the highest attainable external field of $5 \mathrm{~T}$, the magnetization of the nanoscale mechanosynthesized material is about 2 times larger than that of the bulk material. It is, however, also to be recognized at this point that the absolute values of magnetization are very small. They are about two orders of magnitude smaller that those observed in the previously discussed cases of $\mathrm{MgFe}_{2} \mathrm{O}_{4}$ and $\mathrm{NiFe}_{2} \mathrm{O}_{4}$ spinels. In contrast to the latter, in $\mathrm{BiFeO}_{3}$ no indications are observed in the Mössbauer spectra pointing to a changing distribution of cations in the distorted perovskite structure, ${ }^{38)}$ i.e., in contrast to the spinel case, no significant exchange of $\mathrm{Bi}$ and $\mathrm{Fe}$ cations is taking place during the mechanical synthesis.

To explain the origin of the enhanced magnetization of mechanosynthesized $\mathrm{BiFeO}_{3}$ it should be recalled that bulk $\mathrm{BiFeO}_{3}$ is known as an antiferromagnetic compound comprising two spin sublattices with ferromagnetic interactions within each sublattice and antiferromagnetic intersublattice interactions. ${ }^{39)}$ Such a collinear antiparallel spin arrangement results in a zero net magnetic moment due to the complete spin compensation between these two sublattices. However, as has already been pointed out by Néel, ${ }^{40)}$ incomplete spin compensation is possible and it becomes measurable in small-sized particle systems where the long-range antiferromagnetic order is frequently interrupted at the particle surfaces. This results in

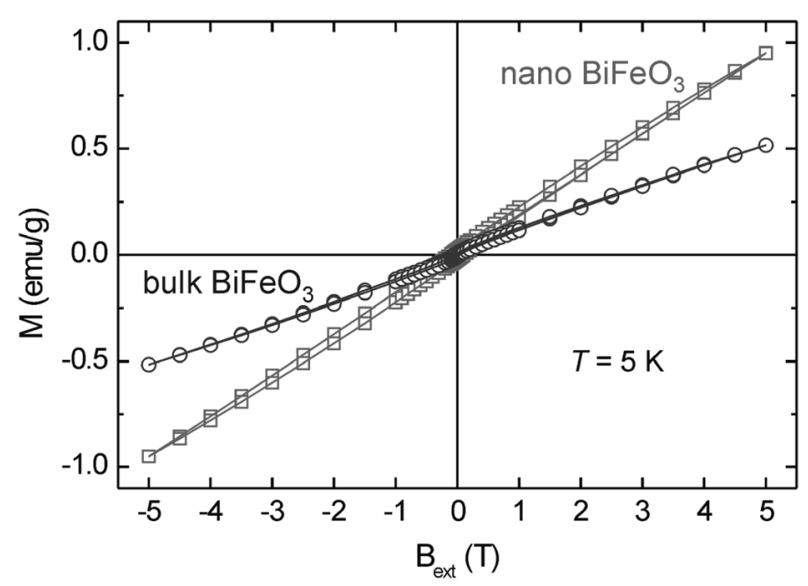

Fig. 13. Magnetizations loops for bulk and nanosized mechanosynthesized $\mathrm{BiFeO}_{3}$ measured at $5 \mathrm{~K}$. 
the small magnetization of the bulk material, Fig. 13, which is about two orders of magnitude smaller than that of the previously discussed magnetic spinels.

In line with this, and taking into account the core-shell structure of the nanosized mechanosynthesized $\mathrm{BiFeO}_{3}$ nanoparticles with an average size of $20 \mathrm{~nm}$ and with shell thicknesses of about $1 \mathrm{~nm},{ }^{38)}$ we attribute the enhanced magnetization of the mechanosynthesized perovskite to the canted (noncollinear) arrangement of spins in the near-surface regions of the nanoferrites which contain about half of the iron cations and which are of amorphous nature. The effect of canted spins in the surface shell of $\mathrm{BiFeO}_{3}$ nanoparticles manifests itself by uncompensated magnetic moments of $\mathrm{Fe}^{3+}$ ions, causing a tangible contribution to the particle's overall magnetization. In fact, the presence of the canted surface spins surrounding an antiferromagnetically ordered core of the as-prepared $\mathrm{BiFeO}_{3}$ nanoparticles is evidenced by the shift of the field-cooled hysteresis loop (exchange bias feature ${ }^{41}$ ) in both horizontal and vertical directions. ${ }^{38)}$

\section{Conclusions}

The case studies presented in this work demonstrate that complex oxide nanomaterials can be synthesized by mechanochemical means. In so far, mechanochemistry as a non-conventional synthesis technique can contribute to the presently ongoing search for novel functional materials using sustainable synthesis routes. With the focus on magnetic properties of mechanosynthesized materials, the examples of $\mathrm{MgFe}_{2} \mathrm{O}_{4}$ and $\mathrm{NiFe}_{2} \mathrm{O}_{4}$ spinels and of the perowskite-type $\mathrm{BiFeO}_{3}$ clearly demonstrate that magnetic properties of such complex nanosized oxides can be significantly different from those of the corresponding bulk materials. The case studies also show that and how these properties of mechanosynthesized nanomaterials can be tailored and varied in a wide range by appropriate treatment.

Finally, focusing on the nanomagnetism of the materials studied, it should be noted that the surface-induced magnetization reported for spinel ferrite nanoparticles ${ }^{31,42}$ (see also Section 2.2.1) is consistently explained in terms of the so-called modified core-shell model, ${ }^{43)}$ in which a competition between the effects of spin canting and site exchange of cations in the surface shell of ferrimagnetic nanoparticles plays a decisive role. According to this model, a magnetization enhancement is observed only in the case when the effect of nonequilibrium cation distribution in the shell dominates over the effect of spin canting; otherwise the usual phenomenon of reduced magnetic moments may be expected for spinel ferrite nanoparticles. ${ }^{37)}$ In the specific case of spinels containing only one magnetic cation species, quite general conclusions can be drawn in the framework of the core-shell model in respect to the variation of their magnetism due to mechanical treatment (mechanosynthesis or mechanical activation). Here, the magnetization of near normal spinels is expected to decrease upon mechanical treatment, whereas for near inverse spinels an increase of magnetization is to be expected. This general conclusion holds also if spin canting in the shell region is taken into account. In contrast to this, the case of the mechanosynthesized $\mathrm{BiFeO}_{3}$ perovskite clearly demonstrates that an enhanced magnetization - albeit at low levels - in a nanoferrite can also be caused as a size effect and by spin canting.

\section{Acknowledgments}

The authors thank the Deutsche Forschungsgemeinschaft (DFG) for the support of their work. K.D.B. acknowledges financial assistance by the WCU Hybrid Materials Program, Seoul National University.

\section{REFERENCES}

1. M. C. Lea, "Disruption of the Silver Haloid Molecule by Mechanical Force," Phil. Mag., 34 [1] 46-50 (1892).

2. L. Takacs, "M. Carey Lea, the First Mechanochemist," J. Mat. Sci., 39 [16-17] 4987-93 (2004).

3. W. Ostwald, Handbuch der Allgemeinen Chemie (in German), Vol. 1, p. 70, Akademische Verlagsgesellschaft, Leipzig, 1919.

4. G. Heinicke, Tribochemistry, p.15, Akademie Verlag, Berlin, 1984.

5. IUPAC. Compendium of Chemical Terminology, 2nd ed. (the "Gold Book"). Compiled by A. D. McNaught and A. Wilkinson. Blackwell Scientific Publications, Oxford (1997). XML on-line corrected version: http://goldbook.iupac.org (2006) created by M. Nic, J. Jirat, B. Kosata; updates compiled by A. Jenkins. ISBN 0-9678550-9-8.

6. S. Kipp, V. Šepelák, and K.-D. Becker, "Mechanochemie: Chemie mit dem Hammer (in German)," Chemie Unserer Zeit, 39 [6] 384-92 (2005).

7. M. K. Beyer and H. Clausen-Schaumann, "Mechanochemistry: The Mechanical Activation of Covalent Bonds," Chem. Rev., 105 [8] 2921-48 (2005).

8. V. V. Boldyrev, "Mechanochemistry and Mechanical Activation of Solids," Russ. Chem. Rev., 75 [3] 177-89 (2006).

9. F. Delogu and G. Mulas, Experimental and Theoretical Studies in Modern Mechanochemistry, Transworld Research Network, Kerala, 2010.

10. V. Šepelák, U. Steinike, D. C. Uecker, S. Wissmann, and K. D. Becker, "Structural Disorder in Mechanosynthesized Zinc Ferrite," J. Solid State Chem., 135 [1] 52-8 (1998).

11. N. Lyakhov, T. Grigorieva, A. Barinova, S. Lomayeva, E. Yelsukov, and A. Ulyanov, "Nanosized Mechanocomposites and Solid Solution in Immiscible Metal Systems," J. Mater. Sci., 39 [16-17] 5421-23 (2004).

12. S. Yin, H. Yamaki, Q. Zhang, M. Komatsu, J. Wang, Q. Tang, F. Saito, and T. Sato, "Mechanochemical Synthesis of Nitrogendoped Titania and its Visible Light Induced $\mathrm{NO}_{\mathrm{x}}$ Destruction Ability," Solid State Ionics, 172 [1-5] 205-9 (2004).

13. M. L. Övecoglu and B. Özkal, "Mechanochemical Synthesis of WC Powders by Mechanical Alloying," Key Eng. Mater., 264-268 [1] 89-92 (2004).

14. E. Avvakumov, M. Senna, and N. Kosova, Soft Mechanochemical Synthesis, Kluwer Academic Pub., Boston, 2001.

15. P. Baláž, Mechanochemistry in Nanoscience and Minerals 
Engineering, Springer, Berlin, 2008.

16. V. Šepelák, I. Bergmann, S. Indris, A. Feldhoff, H. Hahn, K. D. Becker, C. P. Grey, and P. Heitjans, "High-resolution ${ }^{27} \mathrm{Al}$ MAS NMR Spectroscopic Studies of the Response of Spinel Aluminates to Mechanical Action," J. Mat. Chem., 21 [23] 8332-37 (2011).

17. V. Šepelák, K. D. Becker, I. Bergmann, S. Suzuki, S. Indris, A. Feldhoff, P. Heitjans, and C. P. Grey, "A One-step Mechanochemical Route to Core-Shell $\mathrm{Ca}_{2} \mathrm{SnO}_{4}$ Nanoparticles Followed by ${ }^{119} \mathrm{Sn}$ MAS NMR and ${ }^{119} \mathrm{Sn}$ Mössbauer Spectroscopy," Chem. Mater., 21 [12] 2518-24 (2009).

18. C. Deidda, F. Delogu, and G. Cocco, "In Situ Characterisation of Mechanically-induced Self-propagating Reactions," $J$. Mater. Sci., 39 [16-17] 5315-18 (2004).

19. G. Manai, F. Delogu, L. Schiffini, and G. Cocco, "Mechanically Induced Self-propagating Combustions: Experimental Findings and Numerical Simulation Results," J. Mater. Sci., 39 [16-17] 5319-24 (2004).

20. http://www.fritsch.de/.

21. C. Zhou, T. C. Schulthess, and D. P. Landau, "Monte Carlo Simulations of $\mathrm{NiFe}_{2} \mathrm{O}_{4}$ Nanoparticles," J. Appl. Phys., 99 [8] 08H9061-3 (2006).

22. A. Goldman, Modern Ferrite Technology, Springer, New York, 2006

23. T.-J. Park, G. C. Papaefthymiou, A. J. Viescas, A. R. Moodenbaugh, and S. S. Wong, "Size-dependent Magnetic Properties of Single-crystalline Multiferroic $\mathrm{BiFeO}_{3}$ Nanoparticles," Nano Lett., 7 [3] 766-72 (2007).

24. H. Schmalzried, "Röntgenographische Untersuchungen der Kationenverteilung in Spinellphasen (in German)," Z. Physik. Chem. NF, 28 [3/4] 203-19 (1961).

25. H. St. O'Neill and A. Navrotsky, "Simple Spinels: Crystallographic Parameters, Cation Radii, Lattice Energies, and Cation Distribution," Am. Mineral., 68 [1-2] 181-94 (1983)

26. K.D. Becker and F. Rau, "High Temperature Ligand Field Spectra in Spinels: Cation Disorder and Cation Kinetics in $\mathrm{NiAl}_{2} \mathrm{O}_{4}$," Ber. Bunsenges. Phys. Chem., 91 [11] 1279-82 (1987)

27. S. A. T. Redfern, R. J. Harrison, H. St. C. O’Neill, and D. R. R. Wood, "Thermodynamics and Kinetics of Cation Ordering in $\mathrm{MgAl}_{2} \mathrm{O}_{4}$ Spinel up to $1600^{\circ} \mathrm{C}$ from in Situ Neutron Diffraction," Am. Miner., 84 [3] 299-310 (1999).

28. Z. Wong, P. Lazor, S. K. Saxena, and G. Artioli, "High-Pressure Raman Spectroscopic Study of Spinel $\left(\mathrm{ZnCr}_{2} \mathrm{O}_{4}\right)$," J. Solid State Chem., 165 [1] 165-70 (2002).

29. V. Šepelák, S. Indris, P. Heitjans, and K. D. Becker, "Direct Determination of the Cation Disorder in Nanoscale Spinels by NMR, XPS, and Mössbauer Spectroscopy," J. Alloy. Compd., 434-435 [SPEC.ISS] 776-78 (2007).

30. V. Šepelák and K. D. Becker, "Comparison of the Cation Inversion Parameter of the Nanoscale Milled Spinel Ferrites with that of the Quenched Bulk Materials," Mater. Sci. Eng. A, 375-377 [1-2] 861-64 (2004).

31. V. Šepelák, A. Feldhoff, P. Heitjans, F. Krumeich, D. Menzel,
F. J. Litterst, I. Bergmann, and K. D. Becker, "Nonequilibrium Cation Distribution, Canted spin Arrangement, and Enhanced Magnetization in Nanosized $\mathrm{MgFe}_{2} \mathrm{O}_{4}$ Prepared by a One-step Mechanochemical Route," Chem. Mater., 18 [13] 3057-67 (2006).

32. R. E. Vandenberghe and E. De Grave, pp. 115-187 in Mössbauer Spectroscopy Applied to Inorganic Chemistry, Vol. 3. Ed. By G. J. Long, F. Grandjean, Plenum Press, New York, 1989.

33. Joint Committee on Powder Diffraction Standards (JCPDS) Powder Diffraction File, International Centre for Diffraction Data, Newton Square, PA, 2004.

34. M. Muroi, R. Street, P. G. McCormick, and J. Amighian, "Magnetic Properties of Ultrafine $\mathrm{MnFe}_{2} \mathrm{O}_{4}$ Powders Prepared by Mechanochemical Processing," J. Phys. Rev. B, 63 [18] 1844141-7 (2001).

35. K. Haneda and A. H. Morrish, "Noncollinear Magnetic Structure of $\mathrm{CoFe}_{2} \mathrm{O}_{4}$ Small Particles," J. Appl. Phys., 63 [8] 4258-60 (1988).

36. V. Šepelák, D. Baabe, D. Mienert, D. Schultze, F. Krumeich, F. J. Litterst, and K. D. Becker, "Evolution of Structure and Magnetic Properties with Annealing Temperature in Nanoscale High-energy-milled Nickel Ferrite," J. Magn. Magn. Mater., 257 [2-3] 377-86 (2003).

37. V. Šepelák, I. Bergmann, A. Feldhoff, P. Heitjans, F. Krumeich, D. Menzel, F. J. Litterst, S. J. Campbell, and K. D. Becker, "Nanocrystalline Nickel Ferrite, $\mathrm{NiFe}_{2} \mathrm{O}_{4}$ : Mechanosynthesis, Nonequilibrium Cation Distribution, Canted spin Arrangement, and Magnetic Behaviour," J. Phys. Chem. C, 111 [13] 5026-33 (2007).

38. K. L. Da Silva, D. Menzel, A. Feldhoff, C. Kübel, M. Bruns, A. Paesano, Jr., A. Düvel, M. Wilkening, M. Ghafari, H. Hahn, F. J. Litterst, P. Heitjans, K. D. Becker, and V. Šepelák, "Mechanosynthesized $\mathrm{BiFeO}_{3}$ Nanoparticles with Highly Reactive Surface and Enhanced Magnetization," J. Phys. Chem. C, 115 [15] 7209-17 (2011).

39. J. M. Moreau, C. Michel, R. Gerson, and W. J. James, "Ferroelectric $\mathrm{BiFeO}_{3} \mathrm{X}$-ray and Neutron Diffraction Study," J. Phys. Chem. Solids, 32 [6] 1315-20 (1971).

40. L. Néel, "Superparamagnetisme Des Grains Tres Fins Antiferromagnetiques (in French)," Compt. Rend. Acad. Sci., 252 [26] 4075-79 (1961).

41. J. Nogués, J. Sort, V. Langlais, V. Skumryev, S. Surinach, J. S. Munoz, and M. D. Baró, "Exchange Bias in Nanostructures," Phys. Rep., 422 [3] 65-117 (2005).

42. R. N. Bhowmik, R. Ranganathan, R. Nagarajan, B. Ghosh, and S. Kumar, "Role of Strain-induced Anisotropy on Magnetic Enhancement in Mechanically Alloyed $\mathrm{Co}_{0.2} \mathrm{Zn}_{0.8} \mathrm{Fe}_{2} \mathrm{O}_{4}$ Nanoparticle," Phys. Rev. B, 72 [9] 1-10 (2005).

43. V. Šepelák, I. Bergmann, D. Menzel, A. Feldhoff, P. Heitjans, F. J. Litterst, and K. D. Becker, "Magnetization Enhancement in Nanosized $\mathrm{MgFe}_{2} \mathrm{O}_{4}$ Prepared by Mechanosynthesis," $J$. Magn. Magn. Mater., 316 [2] e764-67 (2007). 